\title{
Pengelolaan Obat yang Tidak Terpakai Dalam Skala Rumah Tangga di Kota Bandung
}

\author{
Management of Unused Medicines in Bandung City Households
}

\author{
Anis Puji Rahayu1*, Asti Yunia rindarwati² \\ ${ }^{1}$ Program Studi Farmasi, Fakultas Sains dan Teknologi, Universitas Muhammadiyah Bandung \\ 2 Program Studi Farmasi, STIKES Salsabila Serang \\ Corresponding author: Anis Puji Rahayu; Email: anis.puji.rahayu@hotmail.com \\ Submitted: 08-03-2021 Revised:09-03-2021 Accepted: 12-03-2021
}

\begin{abstract}
ABSTRAK
Obat merupakan komoditas yang memiliki banyak manfaat, namun juga dapat memberikan dampak negatif jika tidak dikelola dengan baik. Salah satu dampak negatifnya adalah obat sisa yang sudah tidak digunakan oleh masyarakat akan menjadi sampah B3 rumah tangga yang membahayakan lingkungan hidup. Mengingat dampak kesehatan dan lingkungan yang cukup besar terkait obat sisa, peneliti melakukan penelitian terkait pengelolaan obat yang tidak terpakai dalam skala rumah tangga. Metode yang digunakan dalam penelitian ini adalah dengan menggunakan metode penelitian analisis kuantitatif. Data diperoleh melalui teknik wawancara menggunakan instrumen berupa kuesioner kepada responden sebanyak 100 (seratus) rumah tangga di Kota Bandung yang dipilih melalui cluster random sampling. Hasil penelitian menunjukkan 86,0\% rumah tangga memiliki obat di rumah yang diperoleh dari fasilitas kesehatan (rumah sakit, klinik, dan puskesmas) (39\%) dan apotek (38\%). Sebanyak 25,53\% dari obat yang dimiliki tidak lagi digunakan dan didominasi oleh golongan analgesik-antipiretik $(6,28 \%)$ dan obat batuk dan flu $(6,69 \%)$. Hampir seluruh responden di Kota Bandung (93\%) membuang obat yang tidak lagi digunakan ke tempat sampah tanpa prosedur yang tepat dan sisanya membuang ke saluran air, dikubur, atau dibakar. Hal ini menunjukkan potensi resiko pencemaran lingkungan yang tinggi dan timbulnya dampak negatif lain dari segi sosial, ekonomi, dan kesehatan. Kata kunci: Obat tidak terpakai; rumah tangga; Kota Bandung
\end{abstract}

\begin{abstract}
Medicine is a commodity that has many benefits, but can also have a negative impact if not managed properly. One of the negative impacts is that the remaining drugs that are no longer used by the community will become hazardous and toxic waste that endangers the environment. Given the considerable health and environmental impacts associated with unused drugs, researchers conducted research related to the management of unused drugs on a household scale. The method used in this research is to use quantitative analysis research method. The data was obtained through interview techniques using instruments in the form of questionnaires to 100 (one hundred) household respondents in Bandung City. The sample has been selected through cluster random sampling methods. The results showed that $86.0 \%$ of households have medicines at home obtained from health facilities (hospitals, clinics, and health centers) (39\%) and pharmacies (38\%). A total of $25.53 \%$ of the drugs were no longer used and dominated by the analgesic-antipyretic group (6.28\%) and cough and flu medicine (6.69\%). Almost all respondents in Bandung (93\%) disposed of drugs in the trash bin without proper procedures with the rest are thrown into the drainage, buried, or burned. This result indicates the potential risk of high environmental pollution and the emergence of negative impacts in terms of social, economic, and health.
\end{abstract}

Keywords: Unused medicines; households; Bandung City

\section{PENDAHULUAN}

Obat telah menjadi komoditas utama yang dikonsumsi oleh seluruh masyarakat di dunia, termasuk di Indonesia (Lu Y, Hernandez P, Abegunde D, 2011). Data dari Dewan Perwakilan Rakyat menunjukkan anggaran belanja kesehatan rata-rata mencapai 19.000 milyar rupiah per tahunnya (Setjen DPR-RI, 2012) termasuk di dalamnya anggaran belanja obat. Rata-rata konsumsi obat masyarakat Indonesia adalah 336.000 rupiah per individu per tahun (Redaksi, 2015a). Jumlah konsumsi obat yang cukup tinggi tersebut merupakan cerminan meningkatnya kesehatan masyarakat karena obat digunakan untuk pencegahan, penyembuhan, pemulihan, peningkatan kesehatan, dan kontrasepsi untuk manusia (Anonim, 2009). Di balik tujuan penggunaan obat terdapat dampak bagi lingkungan yaitu dihasilkannya sampah sisa obat yang tidak dikonsumsi dan obat yang telah kadaluarsa yang ada di ruang lingkup rumah tangga. Sampah 
obat tersebut termasuk ke dalam bahan berbahaya dan beracun (B3) yang harus ditangani dengan hati-hati agar tidak mencemari dan/atau merusak lingkungan hidup atau membahayakan lingkungan hidup, kesehatan, serta kelangsungan hidup manusia dan makhluk hidup lain (Anonim, 2018).

Penelitian sejak tahun 1990 di Amerika Serikat menunjukkan terdeteksinya bahan obat di lingkungan perairan mulai dari air tanah hingga air minum (Kolpin et al., 2002). Pada tahun 2019 peneliti di University of York melakukan penelitian terhadap 14 jenis antibiotik yang umum digunakan dan kemungkinannya ditemukan di sungai berbagai belahan dunia. Hasilnya cukup mencengangkan bahwa $65 \%$ tempat yang diteliti menunjukkan cemaran antibiotik dengan kadar tertinggi berada di Bangladesh yaitu konsentrasi antibiotik 300 kali lipat kadar aman. (Guardian, 2019). Tingginya kadar antibiotik mengancam ekosistem perairan utamanya dengan kemunculan mikroorganisme yang resisten terhadap antibiotik-antibiotik yang ada (Baker and Kasprzyk-Hordern, 2013; Davies, 1996). Tingginya cemaran antibiotik dan obat-obatan lain di ekosistem perairan tak lepas dari perilaku masyarakat dalam membuang sampah obat-obatan, baik pembuangan secara langsung bersama sampah rumah tangga lainnya atau pembuangan langsung ke drainase (kakus atau selokan) (Bound et al., 2006; Tong et al., 2011).

Dalam rangka pencerdasan masyarakat dalam menggunakan obat, pemerintah melalui Kementerian Kesehatan meluncurkan program Gerakan Masyarakat Cerdas Menggunakan Obat (GeMa CerMat) (Redaksi, 2015b). Selain itu dalam mendukung tujuan yang sama, Ikatan Apoteker Indonesia (IAI) selaku wadah berorganisasi profesi apoteker telah menjalankan kampanye program Gerakan Nasional Keluarga Sadar Obat dengan jargon DAGUSIBU (Dapatkan, Gunakan, Simpan, dan Buang obat dengan baik dan benar) sejak tahun 2014 (Redaksi, 2014). Namun kenyataannya sisa dan kemasan obat masih menumpuk di Tempat Pembuangan Sampah (TPS) dan menyumbang persentase sebanyak $11,62 \%$ dari total sampah B3 rumah tangga yang diteliti di Kabupaten Sleman (Iswanto, Sudarmadji, Wahyuni and Sutomo, 2016). Sisa dan kemasan obat di TPS tersebut merupakan salah indikator bahwa masyarakat akan membuang obat yang tidak digunakan bersama sampah lainnya.
Mengingat dampak kesehatan dan lingkungan yang cukup besar terkait obat sisa atau obat yang sudah tidak digunakan masyarakat, peneliti menilai perlu dilakukan penelitian terkait (1) jumlah dan jenis obat berdasarkan golongan terapi yang tidak digunakan dalam skala rumah tangga (2) alasan obat-obatan tersebut tidak digunakan, dan (3) cara membuang obat-obatan yang tidak digunakan tersebut. Penelitian dilakukan di Kota Bandung dengan kepadatan populasi yang cukup tinggi yaitu 660.000 rumah tangga (Badan Pusat Statistik, 2018), dengan harapan menjadi representasi pengelolaan obat sisa oleh masyarakat Indonesia yang berada di daerah perkotaan.

\section{METODOLOGI}

Metode yang digunakan dalam penelitian ini adalah dengan menggunakan metode penelitian analisis kuantitatif (Dr. Priyono, 2008). Data diperoleh melalui teknik wawancara menggunakan instrumen berupa kuesioner yang telah diuji validitas dan reabilitasnya kepada responden rumah tangga di Kota Bandung. Teknik penarikan sampel yang digunakan adalah probability sampling dengan metode cluster random sampling. Jumlah sampel diperoleh sebanyak 100 rumah tangga yang dihitung menggunakan rumus Slovin (Talukder et al., 2016) dengan tingkat kesalahan sebesar $10 \%$. Sampel yang diperoleh dibagi menjadi 5 (lima) cluster wilayah yaitu barat, timur, tengah, utara, dan selatan Kota Bandung. Setiap cluster terdiri dari 20 (dua puluh) rumah tangga yang dipilih secara acak. Penelitian dilakukan di bulan September 2020 selama 10 (sepuluh) hari. Data yang dikumpulkan berupa (1) jumlah dan jenis obat berdasarkan golongan terapi yang tidak digunakan dalam skala rumah tangga (2) alasan obat-obatan tersebut tidak digunakan, dan (3) cara membuang obat-obatan yang tidak digunakan tersebut.

\section{Analisis Data}

Data yang diperoleh pada penelitian ini berupa data karakteristik sosial-demografik, jumlah dan jenis obat berdasarkan golongan terapi yang tidak digunakan dalam skala rumah tangga, alasan obat-obatan tidak digunakan, dan cara membuang obat-obatan yang tidak digunakan. Seluruh data kemudian diberi kode dan dianalisis menggunakan software Microsoft Excel 2016. 
Tabel I. Karakteristik sosial-demografik responden

\begin{tabular}{lc}
\hline Karakteristik Sosial-Demografik & N \\
\hline Jenis Kelamin & \\
Perempuan & 87 \\
Laki-laki & 13 \\
Usia (tahun) & 16 \\
$18-30$ & 33 \\
$30-45$ & 51 \\
$>45$ & \\
Pendidikan Terakhir & 22 \\
SD & 18 \\
SMP & 55 \\
SMA & 5 \\
Diploma/Sarjana & \\
Pekerjaan & 71 \\
Ibu Rumah Tangga & 5 \\
Buruh & 3 \\
Mahasiswa & 11 \\
Wiraswasta & 8 \\
Karyawan & 2 \\
Pensiunan & \\
Kepemilikan Obat di rumah & 86 \\
Memiliki & 14 \\
Tidak memiliki
\end{tabular}

(sumber : Data Primer, 2020)

\section{HASIL DAN PEMBAHASAN}

Responden yang terlibat dalam penelitian ini didominasi oleh perempuan $(87,0 \%)$ dengan pekerjaan sebagai ibu rumah tangga $(71,0 \%)$ sebagai pihak yang berperan utama dalam pengelolaan obat-obatan di rumah. Usia responden beragam, namun sebagian besar (51\%) berusia lebih dari 45 tahun dengan status pendidikan terakhir telah menempuh jenjang SMA (55\%). Data karakteristik sosial-demografik secara lengkap tercantum pada Tabel I.

Jumlah kepemilikan obat-obatan di rumah tangga sangat tinggi yaitu $86,0 \%$ dan hanya $14,0 \%$ total responden yang tidak memiliki obat di rumah. Jumlah ini jauh lebih tinggi dibandingkan survey di negara Ethiopia (Wondimu et al., 2015) dimana kepemilikan obat di rumah cukup rendah (29\%). Hal ini menunjukkan bahwa masyarakat kota Bandung mampu mengakses obat-obatan dengan baik dan terbiasa untuk mengonsumsi obat-obatan. Fasilitas kesehatan (rumah sakit, puskesmas, dan klinik) dan Apotek menjadi tempat utama untuk memperoleh obat seperti tercantum pada Gambar 1. Selain melalui fasiliatas kesehatan dan apotek, masyarakat masih terbiasa memperoleh obat di warung $(23 \%)$ yang menandakan jalur distribusi obat belum sepenuhnya berjalan dengan baik. Diperlukan pengawasan distribusi yang cukup baik supaya obat dapat diperoleh di fasilitas pelayanan kefarmasian yang legal. Hal ini bertujuan untuk mendukung pengobatan rasional (Akici et al., 2018) dan pencapaian luaran terapi pengobatan yang optimal melalui pemberian informasi obat oleh tenaga kefarmasian di fasilitas pelayanan kefarmasian.

Dari keseluruhan obat yang dimiliki sebanyak $25,53 \%$ obat tidak lagi digunakan. Berbagai alasan diungkapkan mengapa obat tidak digunakan, diantaranya menyimpan hanya untuk persediaan (25), sudah sembuh (16), dan tidak cocok (1). Fakta di lapangan menunjukkan $4,36 \%$ obat yang tidak digunakan sudah melewati masa kadaluwarsa. Responden memiliki pemahaman cukup baik terkait tanggal kadaluwarsa yang tercantum pada kemasan obat, dibuktikan dengan $74 \%$ responden dapat menunjukkan tanggal kadaluwarsa pada kemasan obat sedangkan $26 \%$ tidak dapat menunjukkan. Aspek tanggal kadaluwarsa 


\section{Fasilitas Untuk Mendapatkan Obat}

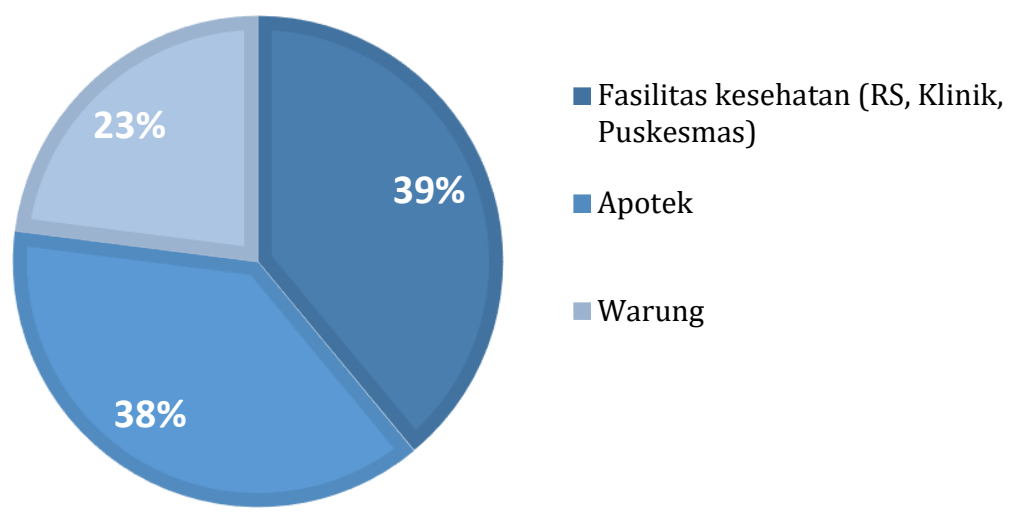

Gambar 1. Fasilitas untuk mendapatkan obat bagi warga Kota Bandung

menjadi salah satu aspek yang banyak diperhatikan $(61 \%)$ oleh responden ketika melakukan pengecekan terhadap kondisi obat yang disimpan dibandingkan bentuk, warna, aroma, dan aspek lainnya.

Hampir seluruh responden mengaku bahwa obat yang tidak lagi digunakan akan langsung dibuang ke tempat sampah (93\%), yang lainnya memilih untuk membuang ke saluran air (2\%), dikubur (1\%), dibakar (1\%), dan cara lainnya (3\%). Sebanyak $70 \%$ responden langsung membuang obat ke tempat sampah tanpa perlakuan/ pemisahan terlebih dahulu, sedangkan 23\% membuang dengan terlebih dahulu memisahkan isi obat dengan kemasan. Tingginya jumlah pembuangan obat sisa ke tempat sampah sejalan dengan penelitian oleh Iswanto, Sudarmadji, Wahyuni and Sutomo, 2016 yang menunjukkan bahwa sampah obat menjadi penyumbang B3 yang signifikan di wilayah Indonesia.

Obat yang paling banyak digunakan oleh masyarakat adalah golongan analgesikantipiretik seperti parasetamol, asam mefenamat, ibuprofen dan lainnya dengan presentase sebesar 33,61\% (Tabel II). Obat jenis ini merupakan obat yang umum ditemui di setiap rumah tangga di seluruh dunia (Law et al., 2014; Nagarani et al., 2014; Tong et al., 2011; Wondimu et al., 2015). Obat lainnya yang mendominasi adalah kelompok obat dengan indikasi batuk dan/ atau flu sebesar 14,71\%. Jenis obat ini banyak diperoleh di rumah tangga di Indonesia dan menjadi golongan obat bebas terbatas dengan penjualan yang cukup tinggi.
Pembuangan sisa/ sampah obat ke tempat sampah merupakan hal yang umum ditemui di negara berkembang seperti Thailand (Nagarani et al., 2014), Ethiopia (Wondimu et al., 2015), Turki (Akici et al., 2018), Malaysia ((Azad et al., 2012) maupun negara maju seperti Amerika Serikat (Law et al., 2014), Inggris (Kusturica et al., 2016), Irlandia (Fenech et al., 2013), dan Selandia Baru (Braund et al., 2009). Meskipun hal ini umum namun dampak negatif terhadap lingkungan hidup sangat signifikan, diantaranya pencemaran tanah dan air akibat residu obat (Baker and Kasprzyk-Hordern, 2013; Bound et al., 2006; Bound and Voulvoulis, 2005; Cunha et al., 2019; Nagarani et al., 2014; Petrie and Camacho-Muñoz, 2020).

Sejak tahun 2000 beberapa peneliti telah melakukan riset terkait residu berbagai obat di lingkungan perairan (Kolpin et al., 2002). Hasilnya sangat memprihatinkan, bahwa di negara maju sekalipun residu obat terdeteksi di air tanah hingga air yang dikonsumsi (Baker and Kasprzyk-Hordern, 2013; Bound and Voulvoulis, 2005). Residu obat yang paling umum ditemukan adalah golongan analgesik (NSAID) (Petrie and Camacho-Muñoz, 2020), dan hormon. Penemuan ini menunjukkan bahwa obat merupakan senyawa yang tidak mudah terurai di lingkungan (Tong et al., 2011) sehingga perlu penanganan khusus, dimulai dari memperoleh hingga membuangnya. Oleh karena itu pemerintah negara-negara maju seperti Amerika Serikat, Inggris, dan Selandia Baru melakukan gerakan untuk mengembalikan obat yang tidak digunakan ke apotek. Pada 
Anis Puji Rahayu, et al

Tabel II. Jumlah dan persentase obat yang disimpan warga Kota Bandung

\begin{tabular}{lcc}
\hline Golongan Obat & $\begin{array}{c}\text { Disimpan di Rumah } \\
\text { N (\%) }\end{array}$ & $\begin{array}{c}\text { Disimpan di Rumah, namun } \\
\text { Tidak Digunakan } \\
\mathbf{N}(\mathbf{\%})\end{array}$ \\
\hline Analgesik-Antipiretik & $80(33,47)$ & $15(6,28)$ \\
Indikasi Batuk/Flu & $35(14,64)$ & $16(6,69)$ \\
Antibiotik & $20(8,37)$ & $8(3,35)$ \\
Kortikosteroid & $19(7,95)$ & $3(1,26)$ \\
Antitukak & $19(7,95)$ & $3(1,26)$ \\
Antihistamin & $12(5,02)$ & $7(2,93)$ \\
Antihipertensi & $11(4,60)$ & $1(0,42)$ \\
Antidiare & $11(4,60)$ & $2(0,84)$ \\
Antidiabetikum oral & $10(4,18)$ & $2(0,84)$ \\
Antihiperlipidemia & $4(1,67)$ & $1(0,42)$ \\
Antiseptik & $3(1,26)$ & $0(0)$ \\
Lain-lain & $15(6,28)$ & $3(1,26)$ \\
TOTAL & 100,00 & 25,53 \\
\hline
\end{tabular}

waktu-waktu tertentu apotek akan memusnahkan obat yang sudah tidak digunakan sesuai dengan jadwal dan lokasi fasilitas pemusnahan (insinerator) yang ditetapkan oleh pemerintah. (Athern et al., 2016; Mackridge and Marriott, 2007)

Pembuangan obat yang tidak sesuai dengan rekomendasi selain memberikan banyak dampak negatif berupa pencemaran tanah, dan air, juga menimbulkan resiko terbentuknya pola resistensi mikroba yang baru terhadap antibiotik. (Baker and KasprzykHordern, 2013; Bound et al., 2006; Davies, 1996). Di sisi lain penelitian terbaru oleh Bertero et al., 2020 menunjukkan bahwa hewan peliharaan (anjing, kucing) dan beberapa hewan yang umum ditemui di lingkungan teracuni oleh keberadaan obat sisa dalam skala rumah tangga. Selain itu permasalahan obat sisa di negara berkembang jauh lebih kompleks ketika obat sisa dalam kemasan utuh disalahgunakan pihak yang tidak bertanggung jawab. Beberapa laporan berita menunjukkan pemulung di beberapa kota di Indonesia terbiasa mengumpulkan obat sisa dari sampah rumah tangga yang kemudian dijual kepada pengepul. (Putra, 2016; Redaksi, 2016). Di sini lah terbuka jalur distribusi ilegal yang dapat membahayakan masyarakat karena dipastikan obat illegal yang dikonsumsi tidak terjamin khasiat, keamanan, dan kualitasnya. Efek jangka panjangnya adalah penurunan kualitas hidup dan derajat kesehatan masyarakat.
Dari segi ekonomi, tingginya jumlah obat yang tidak digunakan mengindikasikan pemborosan (Law et al., 2014). Seharusnya masyarakat bisa lebih berhemat dan menggantikan pengeluaran untuk obat menjadi pengeluaran lain yang sesuai dengan kebutuhan. Dalam skala nasional banyaknya obat yang tidak digunakan menandakan masih belum optimalnya pengelolaan anggaran oleh BPJS Kesehatan karena hampir seluruh masayarakat di Indonesia (umumnya di perkotaan) telah terdaftar sebagai peserta BPJS Kesehatan. Hal ini dibuktikan dengan hasil penelitian ini yang menunjukkan bahwa $76 \%$ responden mengikuti program asuransi kesehatan yang diselenggarakan oleh BPJS Kesehatan. Oleh karena itu pemerintah Indonesia perlu membuat kebijakan yang tepat terkait pengelolaan obat sisa agar berbagai dampak negatif (pencemaran lingkungan, sosial, ekonomi, dan kesehatan) dapat ditekan seminimal mungkin.

Ketidakpahaman masyarakat Indonesia yang direpresentasikan oleh warga Kota Bandung terkait pengelolaan obat ditunjukkan dengan rendahnya informasi yang diterima masyarakat untuk mengeola obat secara tepat. Enam puluh persen repsonden yang terlibat mengaku tidak mengetahui cara pengelolaan (termasuk penyimpanan dan pembuangan) obat yang baik. Hal ini sejalan dengan ketidaktahuan responden (98\%) terhadap program Gema Cermat yang dicanangkan 
Kementerian Kesehatan dan Dagusibu yang dilakukan oleh Ikatan Apoteker Indonesia. Studi yang dilakukan oleh Fenech et al., 2013 menunjukkan edukasi terkait pengelolaan obat sisa oleh penyuluh atau tenaga kesehatan secara langsung ke masyarakat mendapat proporsi yang paling besar dalam kesuksesan pengelolaan obat sisa. Oleh karena itu apoteker sebagai tenaga kesehatan yang bertugas dalam pengelolaan dan edukasi obat-obatan harus berani terjun ke masyarakat dan mengambil peranan yang penting untuk mencerdaskan masyarakat dalam penggunaan obat.

\section{KESIMPULAN}

Warga Kota Bandung memperoleh akses terkait obat-obatan dengan baik. Namun pengelolaan obat sisa tidak dilakukan dengan baik karena 93\% responden membuang obat ke tempat sampah tanpa prosedur yang tepat. Bahaya ketidaktepatan dalam pengelolaan obat sisa diantaranya pencemaran lingkungan, timbulnya mikroba baru yang resisten terhadap antibiotik, munculnya obat ilegal, dan pemborosan dalam keuangan. Pemerintah Indonesia dan Ikatan Apoteker Indonesia perlu memberikan edukasi yang lebih masif dalam pengelolaan obat dan obat sisa kepada masyarakat untuk meminimalisir berbagai dampak negatif yang ditimbulkan.

\section{UCAPAN TERIMAKASIH}

Peneliti mengucapkan terima kasih kepada Direktorat Jenderal Perguruan Tinggi Kementerian Pendidikan dan Kebudayaan Indonesia melalui skema hibah Penelitian Dosen Pemula (PDP) yang telah membiayai secara penuh penelitian ini.

\section{DAFTAR PUSTAKA}

Akici, A., Aydin, V., Kiroglu, A., 2018. Assessment of the association between drug disposal practices and drug use and storage behaviors. Saudi Pharm. J. 26, 7-13.

Anonim, 2009. Undang Undang Republik Indonesia Nomor 36 Tahun 2009 Tentang Kesehatan.

Anonim, 2018. Undang-Undang Republik Indonesia Nomor 18 Tahun 2018 Tentang Pengelolaan Sampah.

Athern, K.M., Linnebur, S.A., Fabisiak, G., 2016. Proper disposal of unused household medications: The role of the Pharmacist. Consult. Pharm. 31, 261-266.
Azad, M.A.K., Ansary, M.R.H., Akhter, M.A., AlMamun, S.M.M., Uddin, M., Rahman, M.M., 2012. Disposal practice for unused medications among the students of the international islamic university Malaysia. J. Appl. Pharm. Sci. 2, 101-106.

Badan Pusat Statistik, 2018. Jumlah Rumah Tangga Menurut Kecamatan di Kota Bandung Tahun 2011-2014 [WWW Document]. URL https://bandungkota.bps.go.id/statictabl e/2017/08/09/73/jumlah-rumahtangga-menurut-kecamatan-di-kotabandung-tahun-2011---2014.html (accessed 12.9.20).

Baker, D.R., Kasprzyk-Hordern, B., 2013. Spatial and temporal occurrence of pharmaceuticals and illicit drugs in the aqueous environment and during wastewater treatment: New developments. Sci. Total Environ. 454455, 442-456.

Bertero, A., Rivolta, M., Davanzo, F., Caloni, F., 2020. Suspected environmental poisoning by drugs, household products and pesticides in domestic animals. Environ. Toxicol. Pharmacol. 80, 103471.

Bound, J.P., Kitsou, K., Voulvoulis, N., 2006. Household disposal of pharmaceuticals and perception of risk to the environment. Environ. Toxicol. Pharmacol. 21, 301-307.

Bound, J.P., Voulvoulis, N., 2005. Household disposal of pharmaceuticals as a pathway for aquatic contamination in the United Kingdom. Environ. Health Perspect. 113, 1705-1711.

Braund, R., Peake, B.M., Shieffelbien, L., 2009. Disposal practices for unused medications in New Zealand. Environ. Int. 35, 952-955.

Cunha, D.L., Mendes, M.P., Marques, M., 2019. Environmental risk assessment of psychoactive drugs in the aquatic environment. Environ. Sci. Pollut. Res. 26, 78-90.

Davies, J., 1996. Origins and evolution of antibiotic resistance. Microbiologia 12, 916.

Dr. Priyono, M.M., 2008. Metode Penelitian Kuantitatif, Revisi 200. ed. Zifatama Publishing, Sidoarjo.

Fenech, C., Rock, L., Nolan, K., Morrissey, A., 2013. Attitudes towards the use and 
disposal of unused medications in two European Countries. Waste Manag. 33, 259-261.

Guardian, 2019. World's rivers “awash with dangerous levels of antibiotics" [WWW Document]. URL https://www.theguardian.com/society/ 2019/may/27/worlds-rivers-awashwith-dangerous-levels-of-antibiotics (accessed 12.9.20).

Iswanto, Sudarmadji, Wahyuni, E.T., Sutomo, A.H.S., 2016. Timbulan Sampah B3 Rumah Tangga dan Potensi Dampak Kesehatan Lingkungan di Kabupaten Sleman, Yogyakarta. J. Mns. dan Lingkung. 23, 179-188.

Kolpin, D.W., Furlong, E.T., Meyer, M.T., Thurman, E.M., Zaugg, S.D., Barber, L.B., Buxton, H.T., 2002. Pharmaceuticals, hormones, and other organic wastewater contaminants in U.S. streams, 1999-2000: A national reconnaissance. Environ. Sci. Technol. 36, 1202-1211.

Kusturica, M.P., Tomas, A., Sabo, A., 2016. Disposal of Unused Drugs: Knowledge and Behavior Among People Around the World. Rev. Enviromental Contam. Toxicol.

Law, A. V, Pharm, B., Ph, D., Sakharkar, P., Pharm, D., H, M.P., Zargarzadeh, A., Pharm, D., Wai, B., Tai, B., Pharm, D., E, A., Hess, K., Pharm, D., Hata, M., Pharm, D., Mireles, R., Pharm, D., Ha, C., Pharm, D., Park, T.J., Pharm, D., D, J., 2014. Taking stock of medication wastage: Unused medications in US households. Res. Soc. Adm. Pharm.

Lu Y, Hernandez P, Abegunde D, E.T., 2011. Medicine expenditures in: The World Medicines Situation 4.

Mackridge, A.J., Marriott, J.F., 2007. Returned medicines: Waste or a wasted opportunity? J. Public Health (Bangkok). 29, 258-262.

Nagarani, N., Kumaraguru, A.K., Devi, V.J., Arkaravichien, W., Benjawilaikul, S., 2014. E nvironment A sia.
Petrie, B., Camacho-Muñoz, D., 2020. Analysis, fate and toxicity of chiral non-steroidal anti-inflammatory drugs in wastewaters and the environment: a review, Environmental Chemistry Letters. Springer International Publishing.

Putra, E.P., 2016. Pemulung_ Satu Setrip Obat Laku Rp 2.000 [WWW Document]. Republika.co.id.

Redaksi, 2014. Sinergisme Program Badan POM RI dengan Ikatan Apoteker Indonesia [WWW Document].

Redaksi, 2015a. Menduga Nasib Pasar Kesehatan Indonesia 2016 [WWW Document]. URL https://www.cnnindonesia.com/gayahidup/20160204082016-255108766/menduga-nasib-pasarkesehatan-indonesia-2016 (accessed 12.9.20).

Redaksi, 2015b. Menkes Canangkan Gerakan Masyarakat Cerdas Menggunakan Obat [WWW Document]. URL http://www.depkes.go.id/article/view/ 15111900001/menkes-canangkangerakan-masyarakat-cerdasmenggunakan-obat.html (accessed 12.9.20).

Redaksi, 2016. Sampah Obat-obatan di TPST Bantargebang akan Diselidiki_Republika Online.

Setjen DPR-RI, 2012. Belanja Fungsi Kesehatan dalam Anggaran Pendapatan dan Belanja Negara (APBN). Menggali Pajak Sekt. Pertamb. Migas dan Non Migas 21-27.

Talukder, A., Alam, G.R., Bairagi, A.K., Abedin, S.F., 2016. Threshold Estimation Models for Influence Maximization in Social Network 888-890.

Tong, A.Y.C., Peake, B.M., Braund, R., 2011. Disposal practices for unused medications around the world. Environ. Int. 37, 292-298.

Wondimu, A., Molla, F., Demeke, B., Eticha, T., Assen, A., 2015. Household Storage of Medicines and Associated Factors in Tigray Region, Northern 1-9. 